\title{
BMJ Open Motion analysis in the field of dentistry: a kinematic comparison of dentists and orthodontists
}

\author{
J Nowak, ${ }^{1}$ C Erbe, ${ }^{2}$ I Hauck, ${ }^{1}$ D A Groneberg,,${ }^{1}$ I Hermanns, ${ }^{3}$ R Ellegast, ${ }^{3}$ \\ D Ditchen, ${ }^{3} \mathrm{D}$ Ohlendorf ${ }^{1}$
}

To cite: Nowak J, Erbe C, Hauck I, et al. Motion analysis in the field of dentistry: a kinematic comparison of dentists and orthodontists. BMJ Open 2016;6: 011559 . doi:10.1136/bmjopen-2016011559

- Prepublication history for this paper is available online. To view these files please visit the journal online (http://dx.doi.org/10.1136/ bmjopen-2016-011559).

Received 18 February 2016 Revised 19 May 2016 Accepted 7 June 2016

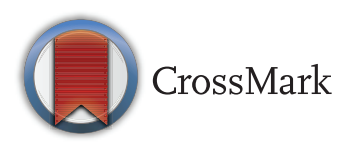

${ }^{1}$ Institute of Occupational Medicine, Social Medicine and Environmental Medicine, Goethe-University Frankfurt/ Main, Frankfurt, Germany ${ }^{2}$ Department of Orthodontics, School of Dentistry, University Medical Centre of the Johannes Gutenberg University Mainz, Mainz, Germany

${ }^{3}$ Institute for Occupational Health and Safety (IFA) of the German Social Accident Insurance (DGUV), Sankt Augustin, Germany

Correspondence to Dr D Ohlendorf; ohlendorf@med.uni-frankfurt. de

\section{ABSTRACT}

Objectives: To conduct a kinematic comparison of occupational posture in orthodontists and dentists in their workplace.

Design: Observational study.

Setting: Dentist surgeries and departments of orthodontics at university medical centres in Germany.

Participants: A representative sample of 21 (10 female, 11 male) dentists (group G1) and 21 (13 female, 8 male) orthodontists (G2) with one male dropout in G2.

Outcome measures: The CUELA (computer-assisted acquisition and long-term analysis of musculoskeletal loads) system was used to analyse occupational posture. Parallel to the recording through the CUELA system, a software-supported analysis of the activities performed (I: treatment; II: office; III: other activities) was carried out. In line with ergonomic standards the measured body angles are categorised into neutral, moderate and awkward postures. Activities between the aforementioned groups are compared using the stratified van Elteren $U$ test and the Wilcoxon-MannWhitney $U$ test. All $p$ values are subject to the Bonferroni-Holm correction. The level of significance is set at $5 \%$.

Results: The percentage of time spent on activities in categories I-II-III was as follows: dentists $41 \%-23 \%-36 \%$ and orthodontists $28 \%-37 \%-35 \%$. The posture analysis of both groups showed, for all percentiles (P5-95), angle values primarily in the neutral or moderate range. However, depending on the activity performed, between $5 \%$ and $25 \%$ of working hours were spent in unfavourable postures, especially in the head-and-neck area. Orthodontists have a greater tendency than dentists to perform treatment activities with the head and torso in unfavourable positions. The statistically significant differences between the two groups with regard to the duration and the relevance of the activities performed confirm this assumption for all three categories $(p<0.01, p<0.05)$.

Conclusions: Generally, both groups perform treatment activities in postures that are in the neutral or medium range; however, dentists had slightly more unfavourable postures during treatment for a greater share of their work day.

\section{Strengths and limitations of this study}

- One strength of this study is separation of the categories into treatment, office and other activities.

- We could combine the kinematic CUELA (computer-assisted acquisition and long-term analysis of musculoskeletal loads) system data with the activities performed.

- One limitation of the CUELA system is the exclusion of fine motor movements in the hands.

- Another limitation is the lack of differentiation between static or dynamic execution of the working tasks.

\section{INTRODUCTION}

The dental profession has a great number of health risks, such as contact allergies, the risk of infection, eye injuries, neuropathy ${ }^{1-5}$ and musculoskeletal disorders of the neck, shoulder and/or back. ${ }^{6-11}$ A questionnaire-based survey of 430 Greek dentists by Alexopoulos et $a l^{7}$ confirms the high incidence of musculoskeletal disorders (62\%). In Poland 92\%, and in Germany $86.7 \%$, of surveyed dentists reported neck or back pain, with $68.6 \%$ of this same group of respondents having disorders every week. ${ }^{8} 12$ A study by Gopinadh et $a l^{13}$ shows that $73.9 \%$ of the 170 surveyed dentists in India have musculoskeletal pain, especially in the neck and back, with the increasing incidence of these symptoms correlating with the number of the hours worked and increased age of the practitioner. More than half of the respondents reported taking poor body postures during treatment.

This problem has been found to lead to the early retirement of dentists. In $29.5-55 \%$ dentists, disorders due to poor body posture are the cause of illness-related retirement. $^{41415}$

A survey of musculoskeletal pain in Indian orthodontists distinguished between those 
who practised exclusively as orthodontists and those who continued to work as dentists also. The prevalence of back pain was observed solely for respondents who worked in the field of orthodontics. ${ }^{16}$ Kerosuo et $a l^{17}$ also reach the conclusion that orthodontists more often complain of pain than dentists.

As a result, ways of integrating optimal and ergonomic posture into the work routine of dentists and orthodontists are increasingly becoming a subject of public interest. To date, there are no data on the postures taken by dentists and orthodontists while working and no comparison between the two groups of unfavourable patterns of posture that might result in musculoskeletal disorders.

Thus, this study used ergonomic and kinematic analysis to investigate patterns of posture in the daily routines of orthodontists and dentists and their possible effect on the development of pain. We investigated the motions and postures of the participating physicians in relation to their professional routine daily activities in three categories: (I) treatment, (II) office and (III) other activities. The following hypotheses were investigated:

1. The treatment stage accounts for the largest temporal share in the day-to-day work of orthodontists and dentists.

2. For both groups unfavourable postures were seen more often during treatment than during office or other activities.

3. In contrast to dentists, orthodontists more often perform treatment with the torso in a neutral position.

\section{METHODS}

\section{Study participants}

Overall, this study measured 42 participants (23 female, 19 male). The participants were divided into two groups: group 1 (G1) comprised 21 dentists (10 female, 11 male) working in established practices in Germany, with an average age of $40.1 \pm 10.4$ years and $10.6 \pm 10.0$ years of work experience; group 2 (G2) comprised 21 orthodontic residents (13 female, 8 male), with an average age of $31.5 \pm 3.8$ years and in training at three university medical centres in Germany. One man was removed from group 2 owing to incorrect measurements. Work experience for group 2 was $3.9 \pm 2.5$ years.

The inclusion criterion was working as a dentist in a private dental clinic or as an orthodontic resident at a university medical centre in Germany. Subjects were sent an official letter containing basic information and if they agreed to participate, they were informed in person about the goals and approach of the study.

All study participants stated that they had no signs of functional impairment of the musculoskeletal system. Previous injuries of the musculoskeletal system had to have occurred more than 2 years before the study. This study was approved by the ethics committee $(135 / 14)$ of Goethe University in Frankfurt am Main. Before the study, all participants gave their written informed consent for participation.
The comparison of postures is expected to show a greater difference between dentists and orthodontists. According to Cohen an effect size with a standard deviation (SD) of $0.8-1$ is considered a significant difference. The power of this study was set at $80 \%$ with approximately 20 study participants.

\section{CUELA measuring system}

The CUELA system (computer-assisted acquisition and long-term analysis of musculoskeletal loads) (figure 1), developed at the Institute for Occupational Safety and Health of the German Social Accident Insurance (IFA; Sankt Augustin/Germany), is used to record and analyse body postures. ${ }^{18}{ }^{19}$ It uses sensors (accelerometers (ADXL 103/203) and gyroscopes (muRata ENC-03R) for head, arms, legs and back, and potentiometers (Contelect) for back torsions) to continuously measure the position and movements of the participants.

A sampling frequency of $50 \mathrm{~Hz}$ and an angular resolution of about $1^{\circ}$ allows objective evaluation of the body postures and motion of participants. ${ }^{20-23}$ Table 1 summarises all study parameters measured and calculated with the CUELA system.

\section{Measuring system: software-based activity analysis}

Participants were observed in their day-to-day work to analyse the activities performed and the motions involved. A hand-held computer (UMPC Samsung Q1,

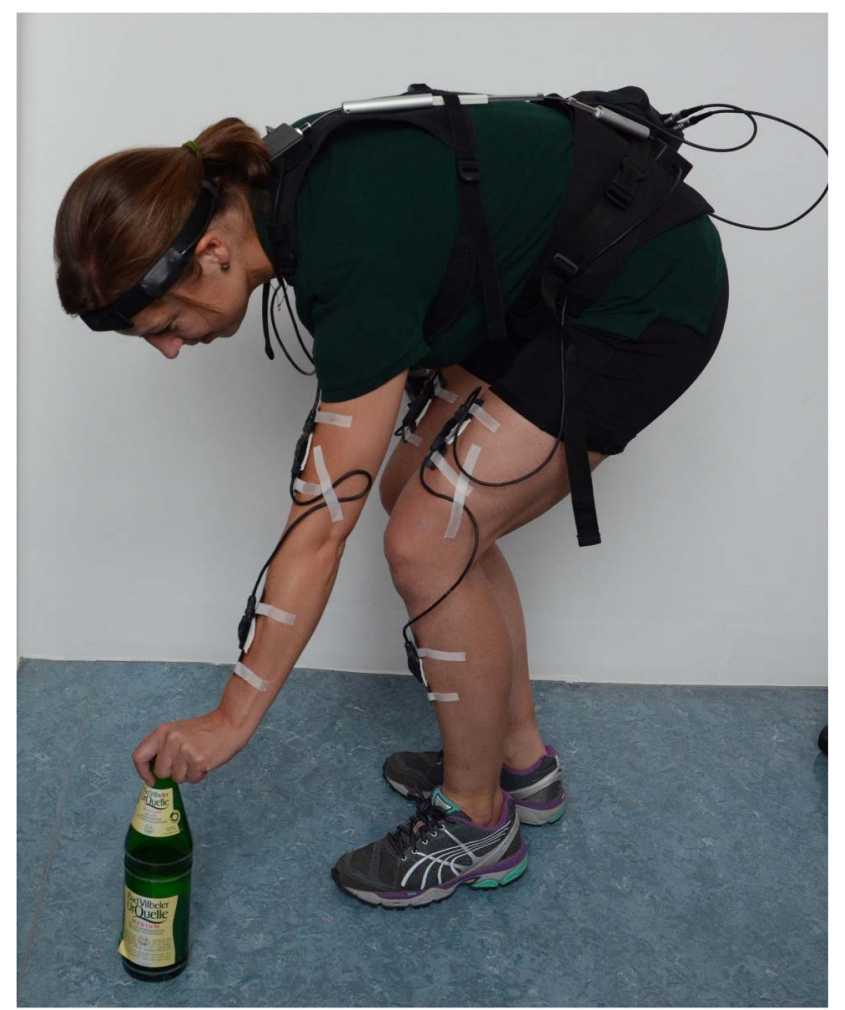

Figure 1 Illustration of the CUELA (computer-assisted acquisition and long-term analysis of musculoskeletal loads) system. Patient consent received. 
Table 1 Illustration of body and joint angles measured with the CUELA system, evaluation parameters used and assessment criteria in line with ergonomic norms

\begin{tabular}{|c|c|c|c|c|}
\hline $\begin{array}{l}\text { Body } \\
\text { areas }\end{array}$ & $\begin{array}{l}\text { Joint/body } \\
\text { area }\end{array}$ & $\begin{array}{l}\text { Degree of freedom } \\
\text { according to medical } \\
\text { definitions }\end{array}$ & Evaluation parameter & $\begin{array}{l}\text { Angle range according to } \\
\text { ergonomic standards }\end{array}$ \\
\hline \multirow[t]{4}{*}{$\begin{array}{l}\text { Head/ } \\
\text { neck }\end{array}$} & \multirow[t]{2}{*}{ Head } & Sagittal inclination & Head tilted to the front $\left(\mathrm{HT}_{-} \mathrm{f}^{2425}\right.$ & $\begin{array}{l}\text { Neutral: } 0 \text { to } 25^{\circ} \\
\text { Moderate: } 25 \text { to } 85^{\circ} \\
\text { Awkward: }<0^{\circ} \text { and }>85^{\circ}\end{array}$ \\
\hline & & Lateral inclination & Head tilted to the right $\left(\mathrm{HT}_{-} \mathrm{r}\right)^{25}$ & $\begin{array}{l}\text { Neutral: }-10 \text { to } 10^{\circ} \\
\text { Awkward: }<-10^{\circ} \text { and }>10^{\circ}\end{array}$ \\
\hline & \multirow[t]{2}{*}{$\begin{array}{l}\text { Cervical } \\
\text { spine }(C S)\end{array}$} & Flexion/extension & $\begin{array}{l}\text { Neck curvature to the front (NC_f) } \\
\text { (difference between head and TS) }^{24} 25\end{array}$ & $\begin{array}{l}\text { Neutral: } 0 \text { to } 25^{\circ} \\
\text { Awkward: }<0^{\circ} \text { and }>25^{\circ}\end{array}$ \\
\hline & & Lateral flexion & $\begin{array}{l}\text { Neck curvature to the right (NC_r) } \\
\text { (difference between head and TS) }\end{array}$ & $\begin{array}{l}\text { Neutral: }-10 \text { to } 10^{\circ} \\
\text { Awkward: }<-10^{\circ} \text { and }>10^{\circ}\end{array}$ \\
\hline \multirow[t]{8}{*}{ Back } & \multirow[t]{2}{*}{$\begin{array}{l}\text { Thoracic } \\
\text { spine (TS) }\end{array}$} & Flexion/extension & TS inclination to the front (TSI_f) ${ }^{24} 25$ & $\begin{array}{l}\text { Neutral: } 0 \text { to } 20^{\circ} \\
\text { Moderate: } 20 \text { to } 60^{\circ} \\
\text { Awkward: }<0^{\circ} \text { and }>60^{\circ}\end{array}$ \\
\hline & & Lateral flexion & TS inclination to the right (TSI_r) 2425 & $\begin{array}{l}\text { Neutral: }-10 \text { to } 10^{\circ} \\
\text { Moderate: }-10 \text { to }-20^{\circ} \\
\text { Moderate: } 10 \text { to } 20^{\circ} \\
\text { Awkward: }<-20^{\circ} \text { and }>20\end{array}$ \\
\hline & \multirow{6}{*}{$\begin{array}{l}\text { Lumbar } \\
\text { spine (LS) } \\
\text { Trunk (T) }\end{array}$} & Flexion/extension & LS inclination to the front (LSI_f) & No ergonomic layout \\
\hline & & Lateral flexion & LS inclination to the right (LSI_r) & available \\
\hline & & \multirow[t]{2}{*}{ Flexion/extension } & $\begin{array}{l}\text { Back curvature to the front }(\mathrm{BC} f \text { ) } \\
\text { (difference between TS and } L S)^{24} 25\end{array}$ & $\begin{array}{l}\text { Neutral: } 0 \text { to } 20^{\circ} \\
\text { Moderate: } 20 \text { to } 40^{\circ} \\
\text { Awkward: }<0^{\circ} \text { and }>40^{\circ}\end{array}$ \\
\hline & & & $\begin{array}{l}\text { Inclination of the torso to the front } \\
(\mathrm{TI} f \text { f) (median flexion of TS and } \\
L S)^{2425}\end{array}$ & $\begin{array}{l}\text { Neutral: } 0 \text { to } 20^{\circ} \\
\text { Moderate: } 20 \text { to } 60^{\circ} \\
\text { Awkward: }<0^{\circ} \text { and }>60^{\circ}\end{array}$ \\
\hline & & Lateral flexion & $\begin{array}{l}\text { Back curvature to the right }\left(\mathrm{BC} \_r \text { ) }\right. \\
\text { (difference between } T S \text { and } L S)^{24} 25 \\
\text { Inclination of the torso to the right } \\
(T I-r) \text { (median lateral flexion of TS } \\
\text { and } L S)^{2425}\end{array}$ & $\begin{array}{l}\text { Neutral: }-10 \text { to } 10^{\circ} \\
\text { Moderate: }-10 \text { to }-20^{\circ} \\
\text { Moderate: } 10 \text { to } 20^{\circ} \\
\text { Awkward: }<-20^{\circ} \text { and }>20^{\circ}\end{array}$ \\
\hline & & Torsion & $\begin{array}{l}\text { Back torsion to the right }\left(\mathrm{BT}{ }^{\mathrm{r}} \text { ) }\right. \\
\text { (difference between } T S \text { and } L S)^{25}\end{array}$ & \\
\hline
\end{tabular}

Samsung Electronics GmbH. Schwalbach, Germany), which relies on data acquisition software, ${ }^{26} 27$ specifically designed for this study, recorded the activities performed in real time each second. This software was coded specifically for each group and their respective treatment spectrum (activity categories). The beginning, duration and end of each orthodontic or dental activity were recorded. A detailed description of the system has been published previously. ${ }^{26} 27$

\section{Experimental procedure}

To summarise and describe the daily activities performed, both groups were observed in their routine for one working day before the study. This detected 22 activities were detected for G1 and 25 for G2, all of which were subsequently divided into three categories: (I) treatment, (II) office and (III) other activities and implemented into the data acquisition software (table 2).

Each participant was studied on a randomly selected work day of 8 hours to ensure an authentic recording of their treatment spectrum. Participants wore the
CUELA system under clothing to conduct the measurement (sensors are attached to arms, legs, head and spine). In parallel with the recording through the CUELA system, two observers logged in real time the activities performed with a hand-held computer. Some activities are summarised in table 2 as 'craft activities' (I) because the two groups do not perform exactly the same activities.

\section{Evaluation}

Once the measurement was completed, the time intervals of the activity analysis (hand-held computer), recorded in real time, were synchronised with the time axis of the motion analysis (CUELA). Specially developed software (IFA; Sankt Augustin, Germany) was used to create visualisations and descriptive analysis of the retrieved results.

The descriptive analysis of the postures observed was based on the arithmetic mean (AM), SD and the percentiles P05, P25, P50, P75 and P95. The percentiles describe the angle values that are below the measuring 
Table 2 Illustration and explanation of categories for the respective activities performed

\begin{tabular}{|c|c|c|}
\hline Category & Work task & Details \\
\hline \multirow[t]{7}{*}{ Treatment } & Impression & Taking an impression of the patient's teeth \\
\hline & Photo & Camera documentation of the case \\
\hline & Craft activities* & $\begin{array}{l}\text { Umbrella term for all work stages that are not included in the aforementioned } \\
\text { activities }\end{array}$ \\
\hline & Palpation & Palpating patients' muscles/jaw joints \\
\hline & Break & Short breaks during treatment \\
\hline & Screening & First/check-up screening of patients \\
\hline & $\begin{array}{l}\text { Contra-angle/ultrasonic } \\
\text { handpiece }\end{array}$ & Using contra-angle/ultrasonic handpiece during treatment \\
\hline \multirow[t]{4}{*}{ Office } & Consult files & Reading patient files (results/tooth model/X-ray) \\
\hline & Office work & Writing entries for patient files/computer work \\
\hline & Model analysis & $\begin{array}{l}\text { Analysis and conception of treatment plans based on teeth models and } \\
\text { X-ray examinations }\end{array}$ \\
\hline & Phone call & Having phone conversations \\
\hline \multirow{6}{*}{$\begin{array}{l}\text { Other } \\
\text { activities }\end{array}$} & Meeting & Medical consultation among peers \\
\hline & Talk & Conversations with patients and staff as solitary activity \\
\hline & Hygiene & Hygienic measures (washing/disinfecting hands, wearing gloves/face masks) \\
\hline & Take/deposit instrument & $\begin{array}{l}\text { Taking up instruments from a drawer/putting instruments down during and } \\
\text { after treatment }\end{array}$ \\
\hline & Laboratory & Any kind of laboratory work \\
\hline & Walk & Covering distances \\
\hline
\end{tabular}

${ }^{*}$ Craft activities in group 1: extraction, pain diagnostics, implantation, placing an injection; and in group 2: archwire-/elastics change, removable appliance, fixed appliance, mini-implant, filling, prophylaxis, splint.

time of the respective activity performed in a particular joint region. For instance, the P05 value describes the threshold value for joint angles, at which $5 \%$ of all measured data do not reach the threshold value and $95 \%$ exceed it. These angle values were subsequently evaluated and assigned to a colour-coded angle range (traffic light system: red/yellow/green) in compliance with ergonomic standards. ${ }^{24} 28$ 29 Based on the respective colours, postures were assessed as unfavourable (awkward), moderate or neutral ${ }^{30}$ (table 1).

Activities of both groups were compared based on the stratified van Elteren test and the bilateral WilcoxonMann-Whitney U test along with the Bonferroni-Holm correction because the data retrieved were not normally distributed under the Kolmogorov-Smirnoff test. After the comparison, only those activities for which sensors showed angle values that were significantly different and relevant to the dental or orthodontic profession were analysed.

\section{RESULTS}

\section{Activity analysis}

On average, data were collected for both groups for about 6 hours each day (total measuring period was G1: 116.4 hours; G2:131.9 hours). The percentage of the measuring period was distributed across the three activity categories I-II-III as follows: G1: $41 \%-23 \%-36 \%$ and G2: $28 \%-37 \%-35 \%$. The duration of activity for each category is shown in figure 2 .

Category (I) comprised seven comparable activities, of which 'craft activities,' contra-angle/ultrasound,' and 'examination/screening' had the longest duration, accounting for $96 \%$ of treatment time in G1 and $90 \%$ in G2. In category (II), 'consult files' and 'office work' accounted for $90 \%$ of office time in G1 and $87 \%$ in G2. 'Talk' (G1: 67\%; G2: 63\%) and 'walk' (G1: 9\%; G2: $14 \%)$ represented the largest shares of category (III). As a result, these category (III) activities accounted for more than three-quarters of the total other activities working time. During the 'walk' and 'talk' category III activities dentists and orthodontists take almost identical postures and, therefore, the statistical analysis of the differences between both groups disregards these postures. Instead, the rarely performed activity 'laboratory' (G1: $7 \%$; G2: 7\%) is analysed.

\section{Descriptive posture analysis}

Table 3 shows the benchmarks for the distribution of body and joint angles (percentile P05, P25, P50, P75 and P95) assumed during the most important activities for orthodontists and dentists.

For the median (P50) for all relevant activities, it is evident that dentists and orthodontists often work in the same angle range, which is predominantly ranked as neutral or moderate (table 3). Neutral postures (table 1) are mainly found between P25 and P75 values. This is the case for the evaluation parameters for inclination of the thoracic spine to the right (TSI_r), back torsion to the right (BT_r), inclination of the torso to the front (TI_f), inclination of the torso to the right (TI_r) and for inclination of the lumbar spine to the right (LSI_r). Moderate posture is found with back curvature to the 


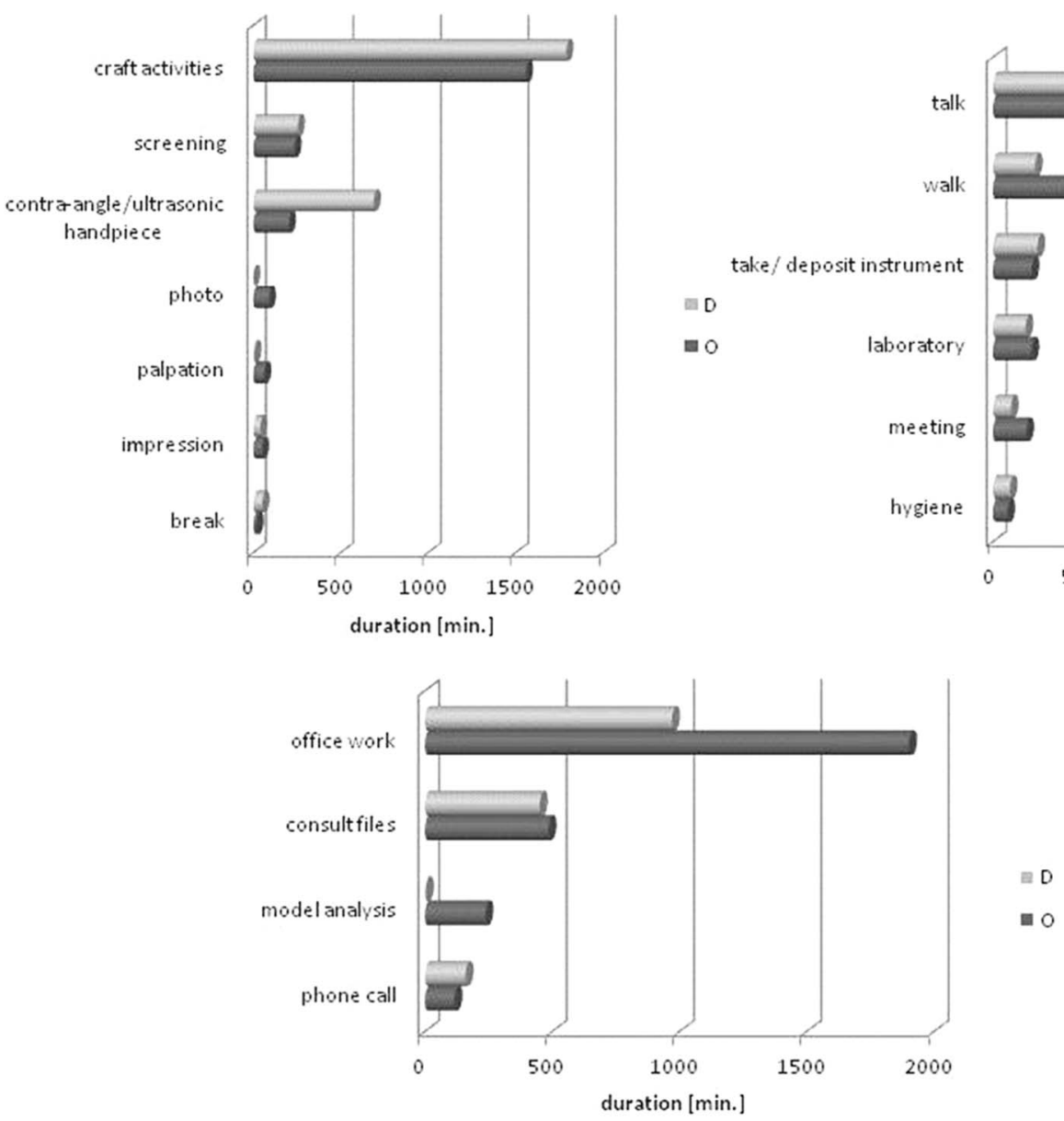

Figure 2 Comparison of temporal duration of activities performed by both professional groups. D, dentist; O, orthodontist.

front (BC_f) and head tilted to the front (HT_f). For both groups inclination of the thoracic spine to the front (TSI_f) is found to be generally neutral for lower percentiles and in the moderate range for higher percentiles.

Unfavourable postures in $\mathrm{P} 05$ and $\mathrm{P} 95$ are primarily found in neck curvature to the right ( $\left.\mathrm{NC}_{-} \mathrm{r}\right)$ and to the front (NC_f) as well as head tilted to the right (HT_r), whereas medial sections are ranked as neutral. In category II for both groups several body and joint angles are predominantly in the neutral range (back curvature to the front (BC_f), inclination of the thoracic spine to the front (TSI_f), inclination of the thoracic spine to the right (TSI_r), head tilted to the front (HT_f), head tilted to the right (HT_r), inclination of the lumbar spine to the right (LSI_r), back torsion to the right (BT_r) and inclination of the torso to the right (TI_r). Several angles are found to be in the moderate range at and above P50 and in the unfavourable range below P50 (neck curvature to the right (NC_r), neck curvature to the front (NC_f), head tilted to the front (HT_f) and right (HT_r), and inclination of the torso to the front (TI_f)). Back curvature to the front (BC_f) prevails in the moderate range. Data retrieved for 'laboratory' (III) are similar to data determined for office (II).
Treatment (I)

Compared with orthodontists, dentists use the contraangle or ultrasonic handpiece more often and for longer $(\mathrm{p}<0.001)$. Group 1 performs this activity 797 times (total duration about $689 \mathrm{~min}$ ) and group 2 only 138 times (total duration about $204 \mathrm{~min}$ ).

Statistically significant differences between the two groups are found for the activity 'examination/screening' in the inclination of the thoracic spine to the front (TSI_f) at P95 $(p<0.05)$, neck curvature to the right $\left(N C_{-} r\right)$ at SD $(p<0.05)$ and P95 $(p<0.05)$, neck curvature to the front $\left(\mathrm{NC}_{-} \mathrm{f}\right)$ at $\mathrm{SD}(\mathrm{p}<0.05)$, head tilted to the right (HT_r) at SD and P95 $(\mathrm{p}<0.05)$ and back curvature to the front $\left(\mathrm{BC}_{-} \mathrm{f}\right)$ at $\mathrm{SD}(\mathrm{p}<0.05)$ (table 4). Classification of the measured angle values according to the various codes is identical for all sensors considered. Nevertheless, angle values are evidently higher in orthodontists than in dentists.

We also observed that both groups always perform 'craft activities' in the same angle range (table 4). Statistical significance is found for the inclination of the thoracic spine to the right (TSI_r) at P05 $(\mathrm{p}<0.05)$, neck curvature to the right $\left(\mathrm{NC} \_r\right)$ at $\mathrm{SD}(\mathrm{p}<0.05)$, neck curvature to the front $\left(\mathrm{NC} \_f\right)$ at $\mathrm{SD}$ and P95 $(\mathrm{p}<0.01$ or $\mathrm{p}<0.05)$, head tilted to the right $\left(\mathrm{HT}_{-} \mathrm{r}\right)$ at $\mathrm{SD}(\mathrm{p}<0.01)$ 
Table 3 Comparative illustration of median posture

\begin{tabular}{|c|c|c|c|c|c|c|c|c|c|c|c|c|c|c|c|c|c|c|c|c|c|c|c|c|c|c|c|c|c|c|c|}
\hline $\begin{array}{l}\text { Descriptive body posture } \\
\text { (P5-25-50-75-95) }\end{array}$ & & Craft & acti & rities & & & Scre & ening & & & & & & & & & Offic & e wor & & & & Cons & sultin & ig file & & & Labo & orator & & & \\
\hline Percentile (in degree ${ }^{\circ}$ ) & & 5 & 25 & 50 & 75 & 95 & 5 & 25 & 50 & 75 & 95 & 5 & 25 & 50 & 75 & 95 & 5 & 25 & 50 & 75 & 95 & 5 & 5 & 50 & 75 & 95 & 5 & 25 & 50 & 75 & 95 \\
\hline TS inclination to the front & $\mathrm{D}$ & 7 & 14 & 19 & 24 & 30 & 7 & 15 & 19 & 23 & 27 & 11 & 20 & 25 & 28 & 31 & 3 & 10 & 14 & 18 & 24 & 5 & 14 & 19 & 23 & 29 & 6 & 12 & 17 & 22 & 30 \\
\hline$\left(\right.$ TSI_f $\left.\left(^{\circ}\right)\right)$ & $\mathrm{O}$ & 8 & 16 & 21 & 26 & 32 & 8 & 17 & 23 & 28 & 35 & 13 & 22 & 26 & 28 & 32 & 9 & 16 & 20 & 24 & 29 & 8 & 14 & 19 & 23 & 29 & 10 & 18 & 23 & 26 & 31 \\
\hline TS inclinati & $\mathrm{D}$ & -5 & 0 & 3 & 6 & 10 & -3 & 3 & 7 & 10 & 15 & -3 & 2 & 4 & 6 & 10 & -5 & -1 & 1 & 4 & 7 & -4 & 0 & 2 & 4 & 8 & -6 & -3 & -1 & 2 & 7 \\
\hline$\left(\right.$ TSI_r $\left.\left(^{\circ}\right)\right)$ & $\mathrm{O}$ & -8 & -3 & 0 & 4 & 9 & -6 & 0 & 4 & 8 & 12 & -5 & -2 & 1 & 5 & 9 & -5 & -2 & 0 & 1 & 4 & -5 & -2 & 0 & 3 & 6 & -5 & -1 & 1 & 2 & 7 \\
\hline Jeck cu & $\mathrm{D}$ & -14 & -5 & 2 & 8 & 17 & -15 & -6 & 1 & 9 & 17 & -13 & -2 & 5 & 12 & 19 & -13 & -7 & -3 & 1 & 6 & -14 & -8 & -4 & -1 & 5 & -17 & -11 & -6 & -2 & 5 \\
\hline igh & 0 & -15 & -4 & 5 & 14 & 26 & -17 & -4 & 6 & 16 & 30 & -14 & -2 & 6 & 14 & 25 & -14 & -7 & -3 & 2 & 9 & -10 & -4 & 0 & 4 & 10 & -11 & -3 & 2 & 6 & 13 \\
\hline to the & $\mathrm{D}$ & -5 & 9 & 17 & 23 & 30 & -3 & 1 & 17 & 23 & 29 & 2 & 14 & 20 & 25 & 30 & -16 & -7 & 0 & 7 & 15 & -16 & -7 & -1 & 5 & 14 & -12 & & 7 & 14 & 22 \\
\hline or & C & -5 & 13 & 23 & 30 & 37 & -8 & 8 & 17 & 24 & 32 & 5 & 21 & 28 & 33 & 39 & -22 & -12 & -4 & 4 & 16 & -16 & -6 & 2 & 8 & 17 & -12 & 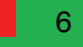 & 18 & 26 & 34 \\
\hline nt & [ & 8 & 25 & 37 & 45 & 54 & 9 & 27 & 36 & 43 & 51 & 17 & 36 & 45 & 51 & 56 & -1 & 0 & 14 & 20 & 29 & 2 & 11 & 17 & 23 & 31 & 3 & 17 & 25 & 32 & 40 \\
\hline & 0 & 8 & 31 & 45 & 53 & 62 & 7 & 28 & 40 & 49 & 59 & 21 & 45 & 54 & 59 & 65 & -2 & 1 & 15 & 23 & 36 & 1 & 13 & 21 & 27 & 36 & 7 & 25 & 41 & 49 & 58 \\
\hline Hea & $D$ & -15 & -4 & 4 & 13 & 25 & -14 & -3 & 8 & 19 & 32 & -13 & 0 & 10 & 19 & 29 & 12 & -6 & -2 & 1 & 8 & -12 & -6 & -2 & 1 & 7 & -17 & -11 & -6 & -2 & 6 \\
\hline$(\mathrm{HT}$ & 0 & -19 & -6 & 5 & 16 & 32 & -19 & -2 & 11 & 24 & 42 & -16 & -3 & 8 & 18 & 31 & 15 & -7 & -2 & 2 & 9 & -10 & -4 & 0 & 4 & 11 & -12 & -3 & 3 & 8 & 15 \\
\hline LS i & $D$ & -14 & -9 & -6 & -3 & 0 & -13 & -9 & -7 & -5 & -2 & -14 & -10 & -7 & -5 & -3 & -25 & -22 & -19 & -15 & -9 & -13 & -8 & -5 & -2 & 2 & -12 & -9 & -6 & -3 & 4 \\
\hline (LS & 0 & -16 & -12 & -9 & -6 & -1 & -17 & -12 & -10 & -5 & -1 & -14 & -10 & -7 & -5 & -2 & 21 & -17 & -13 & -10 & -3 & -16 & -12 & -9 & -6 & -2 & -19 & -15 & -12 & -9 & -2 \\
\hline LS i & $\mathrm{D}$ & -7 & -5 & -3 & -1 & 2 & -8 & -6 & -4 & -2 & 1 & -7 & -4 & -3 & -2 & 1 & -7 & -5 & -3 & -2 & 0 & -8 & -5 & -3 & -1 & 2 & -8 & -6 & -4 & -2 & 2 \\
\hline (LS & 0 & -9 & -6 & -4 & -2 & 2 & -7 & - & -1 & 1 & 5 & -7 & -5 & -4 & -2 & 1 & -7 & -5 & -3 & -2 & 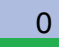 & -7 & -5 & -3 & -2 & 1 & -7 & 3 & -2 & 0 & 3 \\
\hline & $\mathrm{D}$ & - & 3 & 6 & 8 & 11 & 3 & 7 & 11 & 14 & 17 & 2 & 2 & 5 & 7 & 12 & 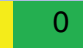 & 3 & 5 & 7 & 10 & - & 3 & 5 & 7 & 11 & -1 & & 3 & 6 & 10 \\
\hline & C & -3 & 1 & 4 & 7 & 11 & -2 & 2 & 5 & 8 & 11 & -1 & 2 & 5 & 8 & 11 & -1 & 1 & 3 & 5 & 8 & -2 & 2 & 4 & 6 & 9 & -3 & 1 & 2 & 4 & 7 \\
\hline to the & $\mathrm{D}$ & 15 & 21 & 25 & 30 & 35 & 16 & 22 & 25 & 29 & 33 & 21 & 28 & 32 & 35 & 38 & 20 & 27 & 33 & 37 & 41 & 13 & 20 & 24 & 27 & 32 & 11 & 18 & 24 & 29 & 34 \\
\hline ron & $\mathrm{O}$ & 17 & 25 & 29 & 34 & 40 & 20 & 27 & 32 & 36 & 41 & 23 & 29 & 32 & 35 & 39 & 20 & 29 & 33 & 37 & 42 & 18 & 24 & 28 & 32 & 36 & 19 & 29 & 35 & 39 & 43 \\
\hline Bach & D & -9 & -5 & -3 & 0 & 7 & -7 & -4 & -1 & 1 & 7 & -6 & -4 & -3 & -1 & 5 & -7 & -3 & 0 & 3 & 6 & -7 & -4 & -1 & 1 & 6 & -6 & -2 & 0 & 2 & 5 \\
\hline (BT & C & -7 & -3 & 0 & 3 & 8 & -6 & -2 & 0 & 3 & 7 & -9 & -6 & -4 & -2 & 6 & -7 & -3 & -1 & 2 & 8 & -6 & -3 & 0 & 3 & 7 & -5 & -1 & 2 & 5 & 10 \\
\hline so to & D & -2 & 3 & 7 & 10 & 14 & -3 & 3 & 6 & 9 & 12 & -1 & 6 & 9 & 11 & 13 & -10 & -5 & -2 & 1 & 6 & -3 & 3 & 7 & 10 & 15 & -1 & 3 & 6 & 8 & 14 \\
\hline & O & -3 & 2 & 6 & 9 & 14 & - & 3 & 7 & 11 & 16 & 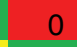 & 6 & 9 & 11 & 15 & -5 & 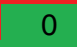 & 4 & 6 & 11 & -3 & 1 & 5 & 8 & 13 & -3 & 2 & 5 & 8 & 12 \\
\hline orso to & $D$ & -5 & -1 & 1 & 3 & 7 & -2 & 0 & 4 & 6 & 10 & -2 & 0 & 2 & 4 & 7 & -5 & -2 & 0 & 2 & 5 & - & -1 & 1 & 3 & 6 & -6 & -3 & -1 & 1 & 5 \\
\hline the right $\left(\mathrm{TI} \_r\left({ }^{\circ}\right)\right)$ & $\mathrm{O}$ & -8 & -4 & -1 & 2 & 7 & -6 & -1 & 3 & 6 & 10 & -5 & -2 & 0 & 3 & 6 & -5 & -2 & -1 & 1 & 4 & -5 & -3 & -1 & 0 & 3 & -5 & -1 & 0 & 2 & 5 \\
\hline
\end{tabular}

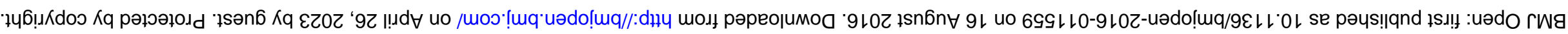


Table 4 Illustration of statistically relevant activities with respective sensors

\begin{tabular}{|c|c|c|c|c|c|c|}
\hline \multicolumn{2}{|l|}{ Activity } & \multirow{2}{*}{$\begin{array}{l}\text { Parameter } \\
\text { P05 }\end{array}$} & Sensor & Orthodontist $\left({ }^{\circ}\right)$ & Dentist $\left({ }^{\circ}\right)$ & Significance \\
\hline Treatment & Craft & & TS inclination to the right (TSI_r) & -8 & -5 & 0.05 \\
\hline & activities & $(\mathrm{MV}) \mathrm{SD}$ & Neck curvature to the right (NC_r) & (5) 13 & (2) 10 & 0.05 \\
\hline & & (MV) SD & Neck curvature to the front (NC_f) & (13) 20 & (15) 11 & 0.01 \\
\hline & & P95 & & 37 & 30 & 0.05 \\
\hline & & $(\mathrm{MV}) \mathrm{SD}$ & Head tilted to the right ( $\left.\mathrm{HT} \_r\right)$ & (5) 16 & (4) 13 & 0.01 \\
\hline & & P05 & $\begin{array}{l}\text { Inclination of the torso to the right } \\
\left(\mathrm{TI} \_ \text {r) }\right.\end{array}$ & -8 & -5 & 0.01 \\
\hline & Screening & P95 & TS inclination to the front (TSI_f) & 35 & 27 & 0.05 \\
\hline & & (MV) SD & Neck curvature to the right (NC_r) & (6) 15 & (1) 10 & 0.05 \\
\hline & & P95 & & 30 & 17 & 0.05 \\
\hline & & (MV) SD & Neck curvature to the front (NC_f) & (15) 13 & (16) 10 & 0.05 \\
\hline & & (MV) SD & Head tilted to the right $\left(\mathrm{HT} \_r\right)$ & (11) 19 & (8) 15 & 0.05 \\
\hline & & P95 & & 42 & 32 & 0.05 \\
\hline & & (MV) SD & Back curvature to the front (BC_f) & (31) 7 & (25) 5 & 0.05 \\
\hline Office (II) & Office work & (MV) SD & Neck curvature to the front ( $\left.\mathrm{NC}_{-} \mathrm{f}\right)$ & $(-4) \pm 12$ & $(0) \pm 10$ & 0.05 \\
\hline $\begin{array}{l}\text { Other } \\
\text { activities (III) }\end{array}$ & Laboratory & $(\mathrm{MV}) \mathrm{SD}$ & Head tilted to the front $\left(\mathrm{HT}_{\mathrm{f}} \mathrm{f}\right)$ & $(37) \pm 16$ & $(24) \pm 2$ & 0.05 \\
\hline
\end{tabular}

and the inclination of the torso to the right (TI_r) at P05 $(\mathrm{p}<0.01)$

\section{Office (II)}

Among orthodontists, 'office work' accounts for $1901 \mathrm{~min}$ - that is, $24 \%$ of the total working hours, which results in a statistical significance in duration of $\mathrm{p}<0.01$. Statistical significance is also found for neck curvature to the front $\left(\mathrm{NC}_{-} \mathrm{f}\right)$ at $\mathrm{SD}(\mathrm{p}<0.05)$. For this activity, orthodontists had greater angle values than dentists $(\mathrm{G} 1<\mathrm{G} 2)$.

\section{Other activities (III)}

The activity 'laboratory' shows a statistical significant difference of $\mathrm{p}<0.05$ in SD for the head tilted to the front (HT_f), with orthodontists having greater angle values than dentists $(\mathrm{G} 1<\mathrm{G} 2)$.

\section{DISCUSSION}

The comparative motion analysis of dentists and orthodontists shows whether a dental or orthodontic activity is performed in an ergonomically favourable body posture or not. The classification of particular activities as 'craft activities' (table 2) and the division of the day-to-day work of both groups into three categories allows for a differentiated analysis of every activity performed and a comparison of both professional groups, showing differences and similarities.

In one working day, treatment (I) accounts for $41 \%$ of time among dentists and $28 \%$ among orthodontists. Orthodontists spent more time in the office $(37 \%)$ or on other activities $(35 \%)$ than on treatment. Therefore, hypothesis 1, which states that the treatment stage accounts for the largest temporal share in the day-to-day work of orthodontists and dentists, is true for dentists and untrue for orthodontists. Increased office work of orthodontists is related to the necessary computer work required for modelling and X-ray analysis, which is considered essential for orthodontic treatment. Among orthodontists 'conversation' is a frequent activity because all stages of the treatment have to be described and explained to the patient, which explains the percentage of $35 \%$ in category III.

Kinematic analysis with the CUELA system enables conclusions to be drawn about the assumed postures. Evaluation of the percentiles $05,25,50,75$ and 95 is particularly significant for hypothesis 2 , which claims that unfavourable postures occur during the treatment of patients. As a result, the classification of body angle data in category I (treatment) emphasises that predominantly neutral or moderate postures are assumed. The range for unfavourable body and joint angles is found in the percentiles P05, P75 and P95 for neck curvature to the right and front ( $\left.\mathrm{NC}_{-} \mathrm{r} ; \mathrm{NC}_{-} \mathrm{f}\right)$, back curvature to the front (BC_f), head tilted to the right (HT_r) and the inclination of the torso to the front (TI_f) (table 3). The data obtained clearly show that for $50 \%$ of the time dentists and orthodontists predominantly carry out treatment in the neutral or moderate angle range. However, for both groups the measured angles, which are all found to be in the moderate range, show greater angle values $\left(25^{\circ}-65^{\circ}\right)$ in the percentiles P25-P95 for inclination of the head to the front during treatment.

For the other two categories (II+III) similar conclusions are drawn: with the activities 'office work,' 'consult files,' and 'laboratory' unfavourable postures in the angles of neck curvature to the right and front (NC_r; 
NC_f), head tilted to the front (HT_f), head tilted to the right (HT_r), inclination of the torso to the front (TI_f) and back curvature to the front (BC_f) are seen. The negative and unfavourable inclination of the head and torso are found to develop owing to a seated position, which enables participants to rest their spine comfortably against the back of the chair, a position which is not considered strenuous.

In comparison with 'office work,' which is performed in the angle range between $7^{\circ}$ and $36^{\circ},{ }^{31}$ treatment is increasingly conducted in a forced posture, particularly seen in the inclination of the head. Angle values in the area of the head and cervical spine differentiate significantly between treatment and office activities, indicating increasing muscular strain during treatment. Thus, participants worked for a greater time during the day in unfavourable positions, which are also the cause of musculoskeletal disorders. This is particularly evident given that the P05 or P95 values of the respective body or joint angles are clearly in the unfavourable range.

The results confirm the already established correlations of musculoskeletal disorders in the dental profession. ${ }^{6-8} 173132$ According to Alexopoulos et $a l^{7}$ more than half of dentists are affected by back, shoulder and/ or neck problems. A comparison of orthodontists and dentists, however, does not show a significant difference in problems due to unfavourable posture.

Consequently, hypothesis 2 is verified - unfavourable postures were seen more often during treatment than during office or other activities. Unfavourable postures in office or other activities correspond to those in other professions. $^{31} 33$

Referring to hypothesis 3 , the measured postures show that there are no great differences in the mode of operation among the two groups, with all participants performing the same activities in the same angle range (neutral or moderate). Angular deviations are found only for 'craft activities' with the inclination of the thoracic spine to the front (TSI_f), 'examination/screening' with the inclination of the thoracic spine to the front (TSI_f), head tilted to the right (HT_r), back curvature to the right (BC_r) and for the activity 'contra-angle/ ultrasonic handpiece' with neck curvature to the front (NC_f). Except for back curvature to the right (BC_r), all angle values for 'examination/screening' among orthodontists were in the worse angle range. Their thoracic spine is seen to incline further to the front and therefore shows a greater extent of frontal neck curvature (unfavourable angle range) (table 3). Consequently, dentists, on average, perform activities in more favourable angle ranges than orthodontists. However, neither of the groups shows only a neutral range of angles during treatment. The $p$ values indicate significant differences between the two groups, even though the angle difference between them is minimal. For instance, this is demonstrated with inclination of TS to the right during the execution of craft activities. The difference in the P05 value accounts for only $3^{\circ}$ ('craft activities' inclination of TS to the right (TSI_r))-G1: $-5^{\circ}$; G2: $-8^{\circ}$ ) (table 4). As a result, the measured angle values are significant but the minimal difference of these angle values is, on the one hand, not clinically relevant and, on the other hand, not crucial for a different angle classification according to ergonomic norms. Consequently, hypothesis 3 is not upheld.

Moreover, a comparison of both groups ought to take their average age into account, which was 9 years lower in the orthodontists than in the dentists (G2: $31.5 \pm 3.8$ vs G1: $40.1 \pm 10.4)$. This age difference together with the greater professional experience (G1: 10.6 \pm 10.0 years; G2: $3.9 \pm 2.5$ years) might also have had an effect on the postures assumed.

As most orthodontists divide their day between working as residents at university medical centres and private practices, they are familiar with private practice routines and apply their experience to their day-to-day work at university medical centres. Moreover, it is worthwhile mentioning that these three university medical centres treat a great number of patients every day. In view of this, the proposed comparison is valid and essential.

The focus of this kinematic analysis is the posture of participants during a particular activity. Here, the individual variance in motion of each participant is given less consideration. Thus the effect of factors such as workplace organisation, treatment position and choice of a patient chair ${ }^{31} 33$ are important components, which can affect people in ways that can cause musculoskeletal disorders. ${ }^{34-37}$

However, musculoskeletal disorders have many causes and develop not only owing to poor posture. Many scientific studies have confirmed that daily stress is a decisive factor. ${ }^{3}{ }^{38-40}$ Consequently, problems of pain among dentists and orthodontists cannot be explained by just one factor and a multifactorial analysis is essential.

Our study is limited because it does not record the fine motor movements of the fingers. As most dental tasks depend on fine motor movement, this aspect should be considered for future studies. Moreover, the study did not consider the potential malposition of the participants' bodies because the measurement was calibrated anew for each participant after the measuring unit/device was attached.

Another limitation of the study is represented by the well-known Hawthorne effect, ${ }^{41}$ which is the phenomenon in which participants change their behaviour once they know they are being observed. In this study, however, this effect should have had little impact on the participants because measurements were made for at least 5 hours in a familiar work environment. In view of this long measurement time, it is unlikely that participants would maintain work habits that deviated markedly from their usual routine. In addition, evaluators remained in the background out of the participants' visual field. In this way, participants hardly noticed the presence of the evaluators and performed their tasks naturally. 
Furthermore, many activities, such as the preparation of a dental crown using a contra-angle piece or cementation of an orthodontic appliance, are performed in longlasting, static positions. These body postures assumed over a long period of time might be the potential cause for the ailments described as work in a static position also results in physical strain. ${ }^{11}$ Analysis of static postures during treatment activities would be a desirable addition to future research in the field.

In summary, the postures analysed in this study do not differ greatly between the two groups surveyed. The same result was found in a survey of the health complaints of dentists $(n=147)$ and orthodontists $(n=81)$ by Kerosuo et al. ${ }^{17}$ Both groups reported a similar prevalence of musculoskeletal disorders, with a slightly increased prevalence among orthodontists $(70 \%$ and $72 \%$, respectively). This slightly higher prevalence is also evident in another study by Sankar et $a .^{16}$ Following ergonomic standards, dentists and orthodontists primarily work in the neutral or moderate range-a conclusion, however, which requires differentiated analysis. Particularly for treatment activities, the P05 or P75-P95 values in the red range emphasise the need for action. These angle values in the red range correlate with prolonged postures in a forced position ( $>4 \mathrm{~s}$ in a static position). ${ }^{25}$ Moreover, apart from the duration of the activity, individual motion control has to be considered as it may lead to muscular imbalance and disorders.

In conclusion, the study emphasises the importance of educating orthodontists and dentists about ergonomic treatment or intensive ergonomic training to prevent musculoskeletal disorders. Furthermore, these results should be taken into account for future studies and used to initiate possible modifications to the work environment of dentists.

Contributors JN, CE, IHa and DO made substantial contributions to the conception and design of the manuscript. JN, CE, IHa, DAG, IHe, RE, DD and DO made substantial contributions to the construction of the measurement protocol. JN and DO carried out the statistical data analysis. All authors read and approved the final manuscript.

Funding This research received no specific grant from any funding agency in the public, commercial or not-for-profit sectors.

Competing interests None declared.

Ethics approval This study was approved by the ethics committee (135/14) of the Goethe University in Frankfurt am Main.

Provenance and peer review Not commissioned; externally peer reviewed.

Data sharing statement No additional data are available.

Open Access This is an Open Access article distributed in accordance with the Creative Commons Attribution Non Commercial (CC BY-NC 4.0) license, which permits others to distribute, remix, adapt, build upon this work noncommercially, and license their derivative works on different terms, provided the original work is properly cited and the use is non-commercial. See: http:// creativecommons.org/licenses/by-nc/4.0/

\section{REFERENCES}

1. Leggat PA, Kedjarune U, Smith DR. Occupational health problems in modern dentistry: a review. Ind Health 2007;45:611-21.
2. Gijbels F, Jacobs R, Princen K, et al. Potential occupational health problems for dentists in Flanders, Belgium. Clin Oral Investig 2006;10:8-16.

3. de Ruijter RA, Stegenga B, Schaub RM, et al. Determinants of physical and mental health complaints in dentists: a systematic review. Community Dent Oral Epidemiol 2015;43:86-96.

4. Burke FJ, Main JR, Freeman R. The practice of dentistry: an assessment of reasons for premature retirement. Br Dent $J$ 1997;182:250-4.

5. Mehta A, Gupta M, Upadhyaya N. Status of occupational hazards and their prevention among dental professionals in Chandigarh, India: a comprehensive questionnaire survey. Dent Res J (Isfahan) 2013;10:446-51.

6. Gupta A, Ankola AV, Hebbal M. Dental ergonomics to combat musculoskeletal disorders: a review. Int J Occup Saf Ergon 2013;19:561-71.

7. Alexopoulos EC, Stathi IC, Charizani F. Prevalence of musculoskeletal disorders in dentists. BMC Musculoskelet Disord 2004:5:16.

8. Kierklo A, Kobus A, Jaworska M, et al. Work-related musculoskeletal disorders among dentists-a questionnaire survey. Ann Agric Environ Med 2011;18:79-84.

9. Sakzewski L, Naser-ud-Din S. Work-related musculoskeletal disorders in dentists and orthodontists: a review of the literature. Work 2014;48:37-45.

10. Hayes M, Cockrell D, Smith DR. A systematic review of musculoskeletal disorders among dental professionals. Int J Dent Hyg 2009;7:159-65.

11. Valachi B, Valachi K. Mechanisms leading to musculoskeletal disorders in dentistry. J Am Dent Assoc 2003;134:1344-50.

12. Meyer VP, Brehler R, Castro HM, et al. Arbeitsbelastungen bei Zahnärzten in niedergelassener Praxis Eine arbeitsmedizinische Bestandsaufnahme zu Wirbelsäulenbelastungen, Berufsdermatosen und Stressfaktoren Deutscher Zahnärzte Verlag DAV-Hanser Köln Mündchen Institut der Deutschen Zahnärzte (IDZ), 2001.

13. Gopinadh A, Devi KN, Chiramana S, et al. Ergonomics and musculoskeletal disorder: as an occupational hazard in dentistry. $J$ Contemp Dent Pract 2013;14:299-303.

14. Brown J, Burke FJ, Macdonald EB, et al. Dental practitioners and ill health retirement: causes, outcomes and re-employment. Br Dent $J$ 2010;209:E7.

15. Hill KB, Burke FJ, Brown J, et al. Dental practitioners and ill health retirement: a qualitative investigation into the causes and effects. Br Dent J 2010;209:E8.

16. Sankar SG, Reddy PV, Reddy BR, et al. The prevalence of work-related musculoskeletal disorders among Indian orthodontists. $J$ Indian Orthod Soc 2012;46:264-8.

17. Kerosuo E, Kerosuo H, Kanerva L. Self-reported health complaints among general dental practitioners, orthodontists and office employees. Acta Odontol Scand 2000;58:207-12.

18. Ellegast RP. Personengebundenes Messsystem zur automatisierten Erfassung von Wirbelsäulenbelastungen bei beruflichen Tätigkeiten. BIA-Report 5/1998. 1998.

19. Ellegast RP. Portable posture and motion measuring system for use in ergomomic field analysis. Landau K, ed. In: Ergonomic software tools in product and workplace design. Stuttgart: Ergon, 2000:47-54.

20. Freitag S, Fincke-Junod I, Seddouki R, et al. Frequent bending-an underestimated burden in nursing professions. Ann Occup Hyg 2012;56:697-707.

21. Glitsch U, Ottersbach HJ, Ellegast R, et al. Physical workload of flight attendants when pushing and pulling trolleys aboard aircraft. Int $J$ Ind Ergon 2007;37:845-54.

22. Kiermayer $\mathrm{C}$, Hoehne-Huckstadt UM, Brielmeier M, et al. Musculoskeletal load in and highly repetitive actions of animal facility washroom employees. J Am Assoc Lab Anim Sci 2011;50:665-74.

23. Ohlendorf $\mathrm{D}$, Schwarzer M, Rey J, et al. Medical work assessment in German hospitals: a study protocol of a movement sequence analysis (MAGRO-MSA). J Occup Med Toxicol 2015;10:1.

24. International Organization for Standardization. ISO 11226 ergonomics-evaluation of static working postures. Geneva, Switzerland: International Organization for Standardisation, 2000

25. Deutsches Institut für Normung. DIN EN 1005-4: Sicherheit von Maschinen-Menschliche körperliche Leistung-Teil 4: Bewertung von Körperhaltungen und Bewegungen bei der Arbeit an Maschinen (01.09). Berlin: Beuth Verlag GmbH, 2009.

26. Mache S, Scutaru C, Vitzthum K, et al. Development and evaluation of a computer-based medical work assessment programme. J Occup Med Toxicol 2008;3:35. 
27. Mache S, Vitzthum K, Kusma B, et al. Pediatricians' working conditions in German hospitals: a real-time task analysis. Eur J Pediatr 2010;169:551-5.

28. Deutsches Institut für Normung. DIN EN 1005-1: Sicherheit von Maschinen-Menschliche körperliche Leistung-Teil 1: Begriffe. Berlin: Beuth Verlag GmbH, 2002.

29. Deutsches Institut für Normung. DIN EN 1005-2: Sicherheit von Maschinen- Teil 2: Menschliche körperliche Leistung; Manuelle Handhabung von Gegenständen in Verbindung mit Maschinen und Maschinenteilen. Berlin: Beuth Verlag GmbH, 2003.

30. Raffler N, Hermanns I, Sayn D, et al. Assessing combined exposures of whole-body vibration and awkward posture-further results from application of a simultaneous field measurement methodology. Ind Health 2010;48:638-44.

31. Groenesteijn L, Ellegast RP, Keller K, et al. Office task effects on comfort and body dynamics in five dynamic office chairs. Appl Ergon 2012;43:320-8.

32. Tirgar A, Javanshir K, Talebian A, et al. Musculoskeletal disorders among a group of Iranian general dental practitioners. $J$ Back Musculoskelet Rehabil 2015;28:755-9.

33. Ellegast RP, Kraft K, Groenesteijn L, et al. Comparison of four specific dynamic office chairs with a conventional office chair: impact upon muscle activation, physical activity and posture. Appl Ergon 2012;43:296-307.
34. Blanc D, Farre P, Hamel O. Variability of musculoskeletal strain on dentists: an electromyographic and goniometric study. Int J Occup Saf Ergon 2014;20:295-307.

35. Custódio RA, Silva CE, Brandão JG. Ergonomics work analysis applied to dentistry--a Brazilian case study. Work 2012;41 (Suppl 1):690-7.

36. Rundcrantz BL, Johnsson B, Moritz U. Cervical pain and discomfort among dentists. Epidemiological, clinical and therapeutic aspects. Part 1. A survey of pain and discomfort. Swed Dent $J$ 1990;14:71-80.

37. Haddad O, Sanjari MA, Amirfazli A, et al. Trapezius muscle activity in using ordinary and ergonomically designed dentistry chairs. Int J Occup Environ Med 2012;3:76-83.

38. Alexander RE. Stress-related suicide by dentists and other health care workers. Fact or folklore? J Am Dent Assoc 2001;132: 786-94.

39. Gupta S. Ergonomic applications to dental practice. Indian J Dent Res 2011;22:816-22.

40. Myers HL, Myers LB. 'It's difficult being a dentist': stress and health in the general dental practitioner. Br Dent J 2004;197:89-93; discussion 83; quiz 100-1.

41. Wickstrom G, Bendix T. The "Hawthorne effect"- what did the original Hawthorne studies actually show? Scand J Work Environ Health 2000;26:363-7. 